\title{
Application of Derivatives in Economic Management
}

\author{
Jianlan Zhou \\ Nanjing Institute of Mechatronic Technology \\ Nanjing, China 211135
}

\begin{abstract}
Derivative belongs to the category of higher mathematics and is also an important concept in higher mathematics. In fact, it is just the way to find the extremum of a function, which is also an abstract reaction to various scientific problems in real life. However, the derivative has a very broad application prospect in social production and economic management. The method of using derivatives to find the extremum of a function is fully used in economic management activities. The derivative is most commonly used in problems of how to control the cost to a minimum in a particular condition, achieve a maximum output, and get the most profit. In this article, the author explores the use of the method of using derivatives to find the extremum of a function in production and economic management.
\end{abstract}

\section{Keywords—economic management; derivative; extremum}

\section{INTRODUCTION}

The analysis of the role of derivative in economic management has important practical value and theoretical significance. For enterprises, scientifically using the method of using the derivative to find the extremum of a function can make them get the best production plan, control the cost to a minimum and obtain the most profit. And, this production plan is scientific. Therefore, the method of using derivatives to find extremum can enable enterprises to take preventive measures in actual production, prepare for the risks that may occur in the future, and realize the optimization and scientific use of resources. Normally, first, it is supposed to find the derivative of the function, use the Fermat Theorem to find the point where $f^{\prime}(x 0)=0$, and then determine whether the extremum is maximum or minimum according to the positive or negative of $\mathrm{f}^{\prime}(\mathrm{x})$ at both sides of $\mathrm{x} 0[1]$.

\section{ELASTICITY ANALYSIS}

The quantity demanded of a kind of commodities is actually influenced by a variety of factors, and these effects can be fully predicted and calculated using elastic analysis. If other factors are regarded as immutable, only the impact of the product price on the demand quantity of the product is cared about, the cross-price elasticities of demand needs to be used[2]. In economics, the cross-price elasticities of demand is described as the change in the quantity demanded of another product when the price of a certain product changes. If the data is positive, it means that the two products studied are substitutes for each other; if the data is negative, it means that the two products studied are complements for each other; if the data is zero, it means that there is no relationship between the two products studied. The example is as follows.
For example: French fries and ketchup are complements for each other, and they are often used in a ratio of 1:1. Find the cross-price elasticities of demand of French fries for ketchup.

The problem-solving idea and method are as follows: Set the demand quantity of fries as A, the price as FA; the demand quantity of tomato sauce as B, the price as FB. For these two complementary products, if the buyer wants to maximize their utilities, there is $\max U(A, B)=\min (A, B)$. Under the premise of $\mathrm{FAA}+\mathrm{FBB}=\mathrm{M}, \mathrm{A}=\mathrm{B}=\mathrm{M} /(\mathrm{FA}+\mathrm{FB})$ can be inferred. The next step is to calculate $\mathrm{eAB}=(\mathrm{dQA} / \mathrm{dFB}) \cdot(\mathrm{FB} / \mathrm{QA})=-$ $\mathrm{FB} /(\mathrm{FA}+\mathrm{FB})<0$. This result fully shows that if the price of tomato sauce increases, the quantity demanded of French fries will decrease. And there is $\lim _{f b \rightarrow \infty} \mathrm{eAB}=-1$, which means that for each $1 \%$ increase in the price of ketchup, the buyer's demand for fries will significantly decrease, and the decrease is infinitely close to $1 \%$.

\section{INVENTORY MANAGEMENT}

For companies, to make the production process smooth and unobstructed, they must prepare the right amount of raw materials. In the condition of a fixed total quantity demanded, the storage costs and the ordering costs are negatively correlated. The reason for this phenomenon is that if the order quantity is large and the frequency is low, the ordering cost is relatively low, but correspondingly the storage fee will increase. How to arrange the order quantity and frequency to make the total cost the lowest in the actual production process is the problem that all enterprise managers will think about carefully. The following is an example.

For example: The annual quantity demanded of $\mathrm{XX}$ production-oriented enterprise for a material is $\mathrm{A}$, the price of the material is $\mathrm{F}$, the cost of each order is $\mathrm{P}$, the annual storage cost rate for finished products is $\mathrm{L}$, the order quantity of each time is $\mathrm{H}$, the purchase period is $\mathrm{D}$, try to calculate the optimal order quantity, frequency, period, and the minimum total cost.

The solution idea and method are as follows: (1) Ordering cost: Set the cost for each ordering to $\mathrm{P}$, and the ordering number in one year to $\mathrm{A} / \mathrm{H}$, then the ordering cost in one year is $\mathrm{PA} / \mathrm{H}$. (2) Storage cost: Since in each purchase period D, there is a maximum inventory at the beginning and the inventory is emptied at the end of the period, the average number of inventories in a year is $1 / 2 \mathrm{H}$, and thus the annual storage cost can be inferred as 1/2HFL. (3) Total cost $\mathrm{U}=\mathrm{PA} / \mathrm{H}+1 / 2 \mathrm{HFL}$. Because there is a functional relationship between the total cost and $\mathrm{H}$, in order to realize the 
optimization of the total cost, it is necessary to let $\mathrm{dU} / \mathrm{dH}=0$, that is, $-\mathrm{PA} / \mathrm{H} 2+1 / 2 \mathrm{~F}=0$. Through the above calculation, we can get the optimal order quantity $\mathrm{H}=\sqrt{ } 2 \mathrm{PA} / \mathrm{F}$, the optimal ordering frequency $=\sqrt{ } \mathrm{AFL} / 2 \mathrm{P}$, the optimal purchase period $=360 \sqrt{ }$ 2P/AFL, the minimum total cost=PA $\sqrt{ }$ $\mathrm{H} / 2 \mathrm{PA}+1 / 2 \mathrm{H} \sqrt{2} \mathrm{PA} / \mathrm{H}=\sqrt{2} 2 \mathrm{PAHL}$.

The above results are calculated on the condition that the required material is originally zero in stock and customized according to the demand, the stock of goods is from zero to the largest amount, and then the supply is equal, and there is no missing or damaged goods. If the sale of products is carried out on average, and the rest of products are considered to be a product inventory, the above method can be used for calculation.

\section{The Production QuAntity That MaKes the Costs THE LOWEST}

In actual production processes, such problems often occur, that is, under certain conditions, how can enterprises arrange production to achieve the lowest cost and highest profit. Assuming that the production quantity of a product of the $\mathrm{XX}$ production enterprise is $\mathrm{A}$ and the total cost is $\mathrm{F}$, then the marginal cost at $\mathrm{A}$ is $F^{\prime}=F^{\prime}(A)$, and the average cost of each product is $\mathrm{g}(\mathrm{A})=\mathrm{F}(\mathrm{A}) / \mathrm{A}$, so $\mathrm{F}(\mathrm{A})=\mathrm{Ag}(\mathrm{A})$, it can be calculated that $F^{\prime}(A)=\mathrm{g}(\mathrm{A})+\mathrm{A}^{g^{\prime}}(\mathrm{A})$. By analyzing the necessary conditions for the existence of the extremum, it can be concluded that the production quantity satisfying $g$ ' $(\mathrm{A} 0)=0$ can minimize the average cost of each product. Putting it into the formula above can give $F^{\prime}\left(A_{0}\right)=$ g (A0), which is also a very valuable conclusion in economics - the production quantity that can make the average cost the lowest is the production quantity at which the average cost and the marginal cost are equal[3]. The average cost is minimized, that is, the total cost is minimized. An example is given below.

For example, assume there is a cost function $F(A)=27+8 A+3 A 2$, find the production quantity that minimizes the average cost.

The problem-solving idea and method are as follows: The average cost $\mathrm{g}(\mathrm{A})=\mathrm{F}(\mathrm{A}) / \mathrm{A}=27 / \mathrm{A}+8+3 \mathrm{~A}$, make $g^{\prime}(\mathrm{A})=-$ $27 / \mathrm{A} 2+3=0$. Solve the equation and it can be calculated that

$\mathrm{A}=3$ is the only solution. Because of $g^{\prime},(\mathrm{A})=54 / \mathrm{A} 3>0$, (when $\mathrm{A}>0$ ), $\mathrm{A}=3$ is the minimum point of the average cost $\mathrm{g}(\mathrm{A})$. In short, $\mathrm{A}=3$ is the production quantity that can minimize the average cost.

\section{CONCLUSION}

In summary, through the author's explanation above, it is not difficult to find that the derivative has high practical value and plays an important role in economic management and companies' production processes. The knowledge used is not only simple but also very practical. However, for students majoring in mathematics, they may not be aware of the application of the knowledge they have learned in production and life. Therefore, they may be weary of studying or drop out of school. But for students majoring in economic management, the above-mentioned knowledge is the content that they must contact, learn, and master in the learning process. In actual cases, organically combining mathematical knowledge and professional knowledge is a good way for students to solve related professional problems. Teaching in this way will make most of the students quickly realize the importance of the knowledge they have learned and gradually develop their interest in learning.

\section{REFERENCES}

[1] Zhu Jianying. Application of derivatives and integrals in economic management [J]. Education Modernization, 2018, 23(3):pp.13-14. 朱建 英. 导数和积分在经济管理中的应用 [J]. 教育现代化, 2018, 23(3):13-14.

[2] Zeng Liuqing. Application of Derivatives in Economic Management and Analysis [J]. Knowledge Economy, 2016, 34(7): pp.140-140. 曾刘 庆. 导数在经济管理和分析中的应用[J]. 知识经济, 2016, 34(7): 140140.

[3] Li Qinghua. The Application of Economic Mathematics in Economic Management[J]. Economic Research Guide, 2017, 31(9): pp.173-174. 李庆华. 经济数学在经济管理中的应用探究 [J]. 经济研究导刊, 2017, 31(9):173-174. 